7. Oznobihina A.O., Gayevaya E.V. Heavy Metals in Soil\&Plant System Under Conditions of the South of Tyumen Region // IOP Conference Series: Materials Science and Engineering (MSE) International Conference on Construction, Architecture and Technosphere Safety, ICCATS 2017. Vol. 262. Chelyabinsk: South Ural State University, 2017. P. 012170.

8. Савич В.И., Седых В.А., Никиточкин Д.Н., Сердюкова А.В., Шестаков А.К., Саидов Е.И. Агроэкологическая оценка состояния почв в системе почва - растение. М.: Изд-во ВНИИА, 2012. 360 с.

9. Барсегян А.Г., Гендугов В.М., Глазунов Г.П. и др. Экологическое нормирование и управление качеством почв и земель. М.: НИА-Природа, 2013. 373 с.

10. Глазовская М.А. Геохимия природных и техногенных ландшафтов. М.: Высшая школа, 1988. 328 с.
11. Сысо А.И. Закономерности распределения химических элементов в почвообразующих породах и почвах Западной Сибири. Новосибирск: Изд-во СО PAH, 2007. $277 \mathrm{c}$.

12. Муха В.Д., Картамышев Н.И., Муха Д.В. Агропочвоведение. М.: КолосС, 2004. С. 480-485.

13. Черников В.А., Грингоф И.Г., Емцев В.Т. Агроэкология. Методология, технология, экономика. М.: КолосС, 2004. 400 c.

14. Витол И.С. Экологические проблемы производства и потребления пищевых продуктов: учебное пособие. М.: Издательский комплекс МГУПП, 2000. $93 \mathrm{c}$.

15. Давыдова С.Л., Тагасов В.И. Тяжелые металлы как супертоксиканты 21 века. М.: Изд-во РУДН, 2002. $140 \mathrm{c}$.

\title{
LIMITS OF SEED GERMINATION OF PHYTOMELIORANTS UNDER CONDITIONS OF HEAVY METALS TOXIC CONCENTRATIONS
}

(C) 2019

Oznobihina Anastasia Olegovna, postgraduate student of Technosphere Safety Department Tyumen Industrial University (Tyumen, Russian Federation)

Abstract. The aim of the study is to conduct biological testing at the initial stages of plant objects viability in the model conditions of heavy metal pollution. The paper presents the results of laboratory experiments to assess the impact of different concentrations of heavy metal salts on the viability of yellow melilot and great trefoil seeds. In the course of the conducted experimental studies the author has been established a direct dependence of the decrease in the indices of germination energy and laboratory germination of seeds with an increase in the concentration of phytotoxicant salts, determined the critical (threshold) concentration of the studied elements and the metal content, in which the processes of growth and development of seeds remain. The concentration of $0,01 \%$ cadmium, zinc, lead and copper was optimal for germination of melilot seeds, where germination was equal to 80\%, 74\%, 69\% and 64\%, respectively. For great trefoil seeds, high germination rates were noted in case of $0,01 \%$ contamination with lead, zinc, cadmium and copper $-82 \%, 80 \%, 77 \%$ and $76 \%$, respectively, and in $0,1 \%$ salt solution of lead, copper and zinc there were recorded $75 \%, 74 \%$ and $72 \%$ of seedlings. Zinc in the concentration of $0,01 \%$ at the initial stages of germination of phytomeliorant seeds stimulated germination energy. The tendency of resistance to pollution by lead, zinc and copper was observed at sprouts of a great trefoil, and to pollution by cadmium the greatest resistance was shown by a melilot yellow. Defining the limits of the leguminous plant seeds germination in the presence of a toxic agent will allow research and development in respect of biological restoration of contaminated soils and can be used in technologically disturbed lands.

Keywords: heavy metals; soil pollution; pollutants; phytomeliorants; clover seeds; alfalfa seeds; germination energy; laboratory germination; phytotoxicity; toxic concentration; threshold concentration; optimal concentration; zinc; copper; cadmium; lead; stability limits.

\section{УДК 595.774.2}

DOI 10.24411/2309-4370-2019-11114

Статья поступила в редакцию 11.10 .2018

\section{О ПОЛОВОЙ СТРУКТУРЕ ПОПУЛЯЦИИ У МУХ-КРОВОСОСОК (DIPTERА, НIPPOВОSCIDAE) РОДА ОRNITHОМYА LATREILLE, 1802 В ЦЕНТРАЛЬНОМ РЕГИОНЕ И НА СЕВЕРЕ РОССИИ}

(C) 2019

\author{
Павлов Александр Владимирович, учитель биологии
}

Муромиевская средняя общеобразовательная школа

(n. Муромиево, Судогодский район, Владимирская область, Российская Федераичя)

Быков Юрий Александрович, научный сотрудник отдела науки и экопросвещения

Наџиональный парк «Мещера» (2. Гусь-Хрустальный, Владимирская область, Российская Федерация)

Матюхин Александр Владимирович, кандидат биологических наук,

научный сотрудник Центра кольцевания птиц

Институт проблем экологии и эволющчи им. А.Н. Северцуова РАН (г. Москва, Российская Федерация)

Аннотация. В данной статье рассматривается соотношение полов в популяциях у мух-кровососок рода Ornithomya Latreille, находящихся на территории Владимирской и Мурманской областей. В ходе кольцевания птиц с 2014 года нами проводится сбор паразитирующих на них мух-кровососок. Всего за четыре года во Владимирской области нами осмотрено 12515 птиц, с которых снято 94 самки и 17 самцов кровососки Ornithomya avicularia L., 1758, а также 142 самки и 37 самцов Ornithomya fringillina Curtis, 1836. На территории Мурманской области в 2016 и 2017 годах с птиц собрано 465 самок и 91 самец Ornithomya chloropus Bergot, 
1901. В результате нашего исследования получен и обобщен оригинальный материал по составу половой структуры популяции у мух-кровососок (Diptera, Hippoboscidae) относящихся к роду Ornithomya Latreille, 1802. Установлено доминирование численности самок над самцами у Ornithomya avicularia, Ornithomya chloropus и Ornithomya fringillina в популяциях, расположенных на территории Владимирской и Мурманской областей РФ. Изучение сезонных изменений половой структуры у вышеуказанных видов показало постепенное снижение численности особей мужского пола на протяжении сезона.

Ключевые слова: половая структура популяции; самцы; самки; мухи-кровососки; паразиты птиц; гематофаги; Владимирская область; Мурманская область; Национальный парк «Мещера»; род Ornithomya; Ornithomya avicularia; Ornithomya chloropus; Ornithomya fringillina; Diptera; Hippoboscidae; кольцевание птиц; частота встречаемости кровососок; сезонная динамика численности кровососок.

\section{Введение}

Мухи-кровососки (Diptera, Hippoboscidae) являются облигатными гематофагами птиц и млекопитающих. Представители рода Ornithomya Latreille, 1802 паразитируют на птицах, благодаря хорошо развитым крыльям могут перемещаться с одного хозяина на другого. Подобный образ жизни определяет медико-ветеринарное значение этих насекомых в природных биоценозах. Вредоносная деятельность мухкровососок (Diptera, Hippoboscidae) сводится не только к непосредственному негативному воздействию на хозяина при укусах во время питания, но и к способности быть переносчиком возбудителей болезней различного происхождения. Из Ornithomya avicularia выделены ДНК возбудителей иксодовых клещевых боррелиозов на юге России [1, с. 145-147; 2 , с. 87]. О распространении кровососками возбудителей бактериальных и вирусных инфекций, простейших и гельминтов сообщает в своей монографии Т.Н. Досжанов [3, с. 187-192].

Изучение мух, относящихся к роду Ornithomya, затруднено тем, что большую часть времени эти насекомые проводят на птицах и лишь изредка их можно наблюдать на других объектах живой природы, в том числе и на человеке [4, с. 149]. Научные публикации, посвященные кровососкам, как правило, сводятся к описанию региональных фаун [5, c. $134 ; 6$, с. $24 ; 7$, с. $84-85 ; 8$, с. $75-77 ; 9$, с. $536 ; 10$, c. 244], в то же время вопросы популяционной регуляции, касающиеся соотношения полов и ее динамики, из-за небольшого объема собранного материала остаются нераскрытыми. Изучение соотношения полов в популяции имеет важное прогностическое значение, поскольку это один из показателей популяционной стабильности. В зависимости от сложившихся условий половая структура в популяциях одного вида может существенно изменяться, отражая, таким образом, генетические, онтогенетические и биогеоценотические факторы, влияющие на конкретную популяцию [11, с. 24]. В отличие от большинства двукрылых, мухи-кровососки не плодовиты. Рождая каждый раз по одной куколке, в течение жизни самка откладывает всего 12-15 куколок через каждые 7-9 дней $[12$, с. 25]. В подобной ситуации любые изменения в соотношении полов могут повлиять на судьбу популяции в целом.

Сведения о соотношении полов у мух-кровососок приводятся в ряде зарубежных и отечественных публикаций. Полученные данные носят противоречивый характер и напрямую зависят от выбранной методики исследования. Так, Бекверт [13, с. 176-179] считает, что точное соотношение полов в популяциях кровососок можно узнать, выводя мух из собранных в естественных условиях куколок (вторичное соотношение полов при рождении). В своей монографии
1953 года Бекверт указывает на результаты ряда исследований по выведению имаго из куколок, в ходе которых соотношение полов было близким к 1:1. Иной результат получается в ходе отлова птиц и сборе с них паразитов (третичное соотношение полов у половозрелых особей). Данные, полученные таким путем, свидетельствуют о преобладании в популяциях кровососок самок над самцами. В ходе кольцевания птиц в Австрии для Ornithomya avicularia L., 1758 соотношение самцов и самок составило 1:11, а для Ornithomya fringillina Curtis, 1836 было 1:9 [14, с. 350]. Многолетние сборы, выполненные на территории Казахстана, показали следующее соотношение самцов и самок для кровососок из рода $\mathrm{Or}$ nithomya: для Ornithomya avicularia - 1:2, для Ornithomya fringillina - 1:3, для Ornithomya chloropus Bergot, 1901 - 1:5 [12, с. 28-29]. В результате проводившихся на территории Карелии паразитологических исследований птиц $[15$, с. 62] для Ornithomya chloropus соотношение самцов и самок составило 1:3. В природных условиях Казахстана рассмотрено сезонное изменение в соотношении полов у Ornithomya avicularia [12, с. 28-29]. Установлено, что в сборах, выполненных в мае, самцы $(66,3 \%)$ численно преобладали над самками $(33,7 \%)$. Затем наблюдалось снижение количества мужских особей и преобладание женских, составившее к сентябрю: самцы $25 \%$, самки $-75 \%$. Таким образом, изучение половой структуры популяций мух-кровососок из рода Ornithomya в различных регионах и в разное время года представляет значительный интерес.

Цель нашей работы - на основе оригинального материала выявить половую структуру популяции у мух-кровососок Ornithomya chloropus, Ornithomya fringillina и Ornithomya avicularia в Центральном регионе (Владимирская область) и на севере России (Мурманская область).

\section{Материалы и методы}

Сборы двукрылых во Владимирской области проводились во время кольцевания птиц с июня по ноябрь 2014-2017 годов. Отлов и кольцевание птиц осуществлялись в окрестностях следующих населенных пунктов Гусь-Хрустального района Владимирской области: г. Гусь-Хрустальный, садового общества Михали, деревни Ягодино (расположена на территории НП «Мещера»). Всего за четыре года исследований было поймано, осмотрено и окольцовано 12515 птиц (2014 г. - 2531 особь, 2015 г. - 2411 особей, 2016 г. - 4419 особей, 2017 г. - 3154 особи). В Мурманской области отлов птиц проводился в окрестностях села Лувеньга в 2016 и 2017 гг. В результате осмотра птиц на них обнаружены следующие мухи-кровососки: Ornithomya chloropus - 556 особей, Ornithomya fringillina - 179 особей, Ornithomya avicularia - 111 особей. 
Павлов А.В., Быков Ю.А., Матюхин А.В.

О половой структуре популяции у мух-кровососок (Diptera, Hippoboscidae)..

03.02 .00 - общая биология

\section{Результаты и обсуждение}

В настоящее время на территории Владимирской области нами выявлено 4 вида мух-кровососок, паразитирующих на птицах: Ornithomya avicularia, Ornithomya fringillina, Ornithomya chloropus и Crataerina pallida Latreille, 1812 [16, c. $27 ; 17$, c. $258 ; 18$, c. 435 ; 19 , с. $236 ; 20$, с. 75]. В октябре 2017 года на большой синице - 2 особи (Parus major) - были обнаружены самец и самка Ornithomya chloropus, самка этого же вида была снята с птенцов мухоловки-пеструшки (Ficedula hypoleuca) в начале июня 2018 года. Вероятно, Ornithomya chloropus с перелетными птицами осенью попадает в центральные регионы России и может быть встречена в единичных экземплярах, не образуя постоянных популяций на данной территории. Из-за крайне малого количества обнаруженных особей Ornithomya chloropus анализ соотношения полов у мух, собранных во Владимирской области, не входит в рамки данной публикации.

Ограничение отлова птиц в момент гнездования и выведения птенцов не дает возможности точно отследить сезонную динамику численности паразитических мух. Самое раннее обнаружение Ornithomya avicularia в Центральном регионе зафиксировано нами в апреле 2007 г., когда муха этого вида была снята с пойманной в Москве обыкновенной пустельги (Falco tinnunculus). Последние мухи (две самки, одна из которых несла в брюшке куколку) обнаружены 21.10.2017 г. на мохноногом сыче (Aegolius funereus), пойманном во Владимирской области. С первой декады июня по третью декаду сентября Ornithomya avicularia регулярно отмечается на различных видах птиц. Анализ подекадного распределения птиц, несущих на себе кровососок Ornithomya avicularia, позволяет предположить снижение пика численности у данного вида в конце июля - начале августа. Основываясь на значительном количестве осмотренных мух-кровососок, мы попытались рассмотреть половую структуру популяции и её динамику у Ornithomya avicularia на территории Владимирской области. Отмечается численное преобладание самок над самцами. У Ornithomya avicularia ocoби женского пола встречаются в 5,5 раз чаще, чем мужского (определено $94(84,6 \%)$ ㅇ и $17(15,3 \%) \widehat{\jmath}$ кровососок). В течение сезона наблюдается постепенное снижение численности особей мужского пола (табл. 1). Беременные самки, несущие в брюшке куколку, встречаются вплоть до конца сезона (в сентябре и октябре).

Мухи-кровососки Ornithomya fringillina в центре России массово появляются на птицах во второй декаде июля, в то время как первые, единичные насекомые могут быть встречены уже в конце июня (в зависимости от погодных условий). Паразитирование продолжается до второй декады ноября (18.11.2017). Максимум численности данного вида кровососок приходится на конец июля - начало августа. С начала сентября наблюдается постепенное снижение числа птиц, несущих на себе паразитов. Количество самок Ornithomya fringillina превосходит количество самцов в 3,8 раза (определено 142 $(79,3 \%)$ и $37(20,7 \%) \precsim$ кровососок). В течение сезона у данного вида также наблюдается снижение численности особей мужского пола (табл. 2). При этом на пике численности, в августе, количество пойманных самок и самцов приблизительно равно.

таблица 1 - Соотношение полов у Ornithomya avicularia в течение сезона, по результатам сборов 20142017 гг.

\begin{tabular}{|c|c|c|c|c|c|c|c|c|c|}
\hline \multicolumn{2}{|c|}{ июнь } & \multicolumn{2}{|c|}{ июль } & \multicolumn{2}{|c|}{ август } & \multicolumn{2}{|c|}{ сентябрь } & \multicolumn{2}{|c|}{ октябрь } \\
\hline$\hat{0}$ & q & 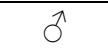 & q & $\hat{0}$ & q & 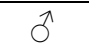 & q & $\hat{0}$ & q \\
\hline 7 & 24 & 6 & 35 & 3 & 21 & 1 & 12 & 0 & 2 \\
\hline $22,5 \%$ & $77,5 \%$ & $14,6 \%$ & $85,4 \%$ & $12,5 \%$ & $87,5 \%$ & $7,7 \%$ & $92,3 \%$ & $0 \%$ & $100 \%$ \\
\hline
\end{tabular}

Таблица 2 - Соотношение полов у Ornithomya fringillina в течение сезона, по результатам сборов 20142017 гг.

\begin{tabular}{|c|c|c|c|c|c|c|c|c|c|}
\hline \multicolumn{2}{|c|}{ июль } & \multicolumn{2}{|c|}{ август } & \multicolumn{2}{|c|}{ сентябрь } & \multicolumn{2}{|c|}{ октябрь } & \multicolumn{2}{|c|}{ ноябрь } \\
\hline$\widehat{0}$ & q & 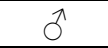 & q & o & q & $\hat{0}$ & q & $\hat{0}$ & q \\
\hline 6 & 36 & 27 & 31 & 4 & 30 & 0 & 38 & 0 & 7 \\
\hline $14,3 \%$ & $85,7 \%$ & $46,5 \%$ & $53,5 \%$ & $11,8 \%$ & $88,2 \%$ & $0 \%$ & $100 \%$ & $0 \%$ & $100 \%$ \\
\hline
\end{tabular}

Единственным представителем рода Ornithomya, встречающимся на птицах на территории Мурманской области, является Ornithomya chloropus. Это полигостальный эктопаразит обнаружен на 81 виде птиц [12, с. 57]. Кровососки массово появляются в августе. Часто на одной птице отмечается несколько мух. Насекомых настолько много, что нам неоднократно встречались спаривающиеся на птице самцы и самки. Собранный в 2016 и 2017 году материал показывает преобладание самок над самцами в 5 раз (определено $465(83,6 \%)$ и $91(16,4 \%) \hat{\jmath}$ кровососок). К сожалению, ограниченность во времени не позволила выяснить сезонную динамику данного вида в Мурманской области. Результаты наших сборов приведены в таблице 3 .
Таблица 3 - Соотношение полов у Ornithomya chloropus в августе и сентябре, по результатам сборов 2016-2017 гг.

\begin{tabular}{|c|c|c|c|}
\hline \multicolumn{2}{|c|}{ август } & \multicolumn{2}{c|}{ сентябрь } \\
\hline$\widehat{\partial}$ & $q$ & $\ddots$ & $q$ \\
\hline 79 & 388 & 12 & 77 \\
\hline $16,9 \%$ & $83,1 \%$ & $13,5 \%$ & $86,5 \%$ \\
\hline
\end{tabular}

Таким образом, общей тенденцией для мухкровососок рода Ornithomyа является преобладание в популяциях особей женского пола над особями мужского пола, постепенное снижение численности особей мужского пола на протяжении сезона. 
Павлов А.В., Быков Ю.А., Матюхин А.В.

\section{Заключение}

Как показали результаты исследований, проведенных нами на территории Владимирской области, частота встречаемости мух-кровососок на птицах невелика. На протяжении 2014-2017 годов Ornithomya avicularia была обнаружена на 51 птице (частота встречаемости 0,4\%), а Ornithomya fringillina на 188 птицах (частота встречаемости 1,5\%). У всех рассмотренных видов наблюдается преобладание самок над самцами. Поскольку самцы гиппобосцид так же, как и самки, питаются кровью, а значит, наравне с последними должны находиться на теле жертвы, их небольшое количество свидетельствует о слабой приспособленности особей мужского пола к активной жизни. Так как куколки кровососок произвольно рассеяны в окружающей среде, период поиска хозяина является одной из критических стадий жизненного цикла насекомых. Мухи поджидают птиц, находясь на ветвях деревьев и кустарников, и нападают на движущиеся объекты, в том числе и на человека (нам дважды приходилось снимать с себя самок Ornithomya avicularia в смешанном лесу). На птицах, а также в их гнездах происходит встреча половых партнеров у кровососок. В условиях невысокой численности в природных биотопах, а также низкой рождаемости преобладание особей женского пола, вероятно, обеспечивает более интенсивный рост популяции. Помимо этого, в соответствии с теорией дихронной эволюции полов Геодакяна [21, с. 5], особи противоположного пола по-разному реагируют на изменения, происходящие в среде. Существует зависящее от условий окружающей среды равновесие в соотношении полов. В оптимальной среде это равновесие сдвигается в сторону увеличения числа самок, в экстремальной - самцов. Согласно этому утверждению доминирование самок над самцами в популяциях свидетельствует об их стабильности, а значит, об устойчивости и самих биоценозов. Для выяснения общих закономерностей необходимо продолжить изучение половой структуры популяции и у других представителей семейства Hippoboscidae.

\section{Список литературы:}

1. Забашта М.В., Пичурина Н.Л., Савченко А.П., Романова Л.В., Матюхин А.В., Забашта А.В. Особенности циркуляции возбудителей р. Borellia на юге России // Актуальные проблемы болезней, общих для человека и животных. Ставрополь, 2017. С. 145-147.

2. Забашта М.В., Пичурина Н.Л., Савченко А.П., Романова Л.В., Бородина Т.Н., Матюхин А.В., Забашта А.В. Фауна и эпизоотологическое значение кровососущих членистоногих Нижнего Дона // Современная паразитология - основные тренды и вызовы: мат-лы VI съезда Паразитологического общества: междунар. конф. (15-19 октября 2018 г., ЗИН РАН, Санкт-Петербург). СПб., 2018. С. 87.

3. Досжанов Т.Н. Мухи-кровососки Казахстана. Алма-Ата: Изд-во «Наука» Казахской ССР, 1980. 208 с.

4. Павлов А.В. Экологические группы мух-гематофагов по степени связи с жильем и хозяйственными постройками человека на территории Владимирской области // Материалы I всерос. совещания по кровососущим насекомым. СПб., 2006. С. 148-150.

5. Матюхин А.В. Паразитологические исследования птиц: мухи-кровососки (Hippoboscidae) Восточной Европы // Труды Центра паразитологии. Биоразнообразие и экология паразитов. М., 2010. T. XLVI. C. $134-147$.
6. Смирнова Ю.Г. Фауна и экология паразитических членистоногих у птиц Ивановской области: автореф. дис. ... канд. биол. наук. Иваново, 2002. 26 с.

7. Шумило Р.А., Лункашу М.И. К Кровососущие мухи Carnidae и Hippoboscidae у птиц ДнестровскоПрутского междуречья // Паразиты животных и растений. Т. 8. Кишинев, 1972. С. 84-85.

8. Столбов Н.M. Кровососки (Diptera, Hippoboscidae) - паразиты птиц в лесной зоне Западной Сибири // Вопросы краевой патологии. Тюмень, 1970. С. 75-77.

9. Бойко А.В., Аюпов А.С., Ивлиев В.Г. Кровососки (Diptera, Hippoboscidae) птиц в природных очагах клещевого энцефалита лесостепной зоны Среднего Поволжья // Паразитология. 1973. № 6. С. 536-540.

10. Труфанова Е.И. Эктопаразиты воробьинообразных птиц в Воронежской области // Современная паразитология - основные тренды и вызовы: мат-лы VI съезда Паразитологического общества: междунар. конф. (15-19 октября 2018 г., ЗИН РАН, Санкт-Петербург). СПб., 2018. С. 244.

11. Яблоков А.В. Популяционная биология. М.: Высшая школа, 1987. 303 с.

12. Досжанов T.Н. Мухи-кровососки (Diptera, Hippoboscidae) Палеарктики. Алматы: Наука, 2003. 277 с.

13. Bequaert J.C. The Hippoboscidae or louse-flies (Diptera) of mammals and birds. 1. Structure, physiology and natural history // Entomologica Americana. 1953. Vol. 32. P. 1-209.

14. Kasparek M., Walter G. Die Lausfliegen-Fauna der Durchzugler und Brutvogel des NeusiedlerseeGebietes (Diptera: Hippoboscidae) // Zeitschrift für angewandte Zoologie. 1986. Vol. 73. P. 345-355.

15. Матюхин А.В., Артемьев А.В., Панов И.Н. Паразитологические исследования птиц: мухикровососки (Hippoboscidae, Ornithomyinae) Карелии // Труды Карельского научного центра РАН. 2017. № 7. С. 60-72.

16. Быков Ю.А., Павлов А.В. Некоторые результаты изучения видового состава и частоты встречаемости мух-кровососок (Diptera, Hippoboscidae) на птицах в северо-восточной части Мещеры // Труды Окского государственного природного биосферного заповедника. Рязань, 2015. Вып. 34. С. 24-28.

17. Павлов А.В. Мухи-кровососки (Diptera, Hippoboscidae) - паразиты птиц в северной части Мещеры // X всерос. диптерологический симпозиум: сборник материалов. Краснодар, 2016. С. 257-260.

18. Быков Ю.А., Павлов А.В. Видовой состав и частота встречаемости мух-кровососок на птицах в северной части Мещеры // Материалы XXI межрегион. краеведческой конф. Владимир, 2017. С. 431-435.

19. Павлов А.В., Быков Ю.А., Матюхин А.В. Мухи-кровососки (Diptera, Hippoboscidae) - паразиты птиц в лесных биотопах северо-восточной части Мещерской низменности // Российский паразитологический журнал. 2017. Т. 41, вып. 3. С. 236-241.

20. Быков Ю.А., Павлов А.В. Мухи (Diptera, Insecta) - паразиты птиц и млекопитающих на территории национального парка «Мещера» // Особо охраняемые природные территории: современное состояние и перспективы развития: мат-лы всерос. юбилейной науч.-практ. конф., посв. 25-летию национального парка «Мещера». 5-6 октября 2017 г. Владимир, 2018. С. 74-78.

21. Геодакян В.А. Дифференциальная смертность полов и норма реакции // Биологический журнал Армении. 1973. Т. 26, № 6. С. 3-11. 


\section{SEXUAL STRUCTURE OF THE BLOODSUCKERS-FLIES (DIPTERA, HIPPOBOSCIDAE) POPULATION OF THE GENUS ORNITHOMYA LATREILLE, 1802 IN THE CENTRAL REGION AND NORTHERN PART OF RUSSIA}

(C) 2019

Pavlov Aleksandr Vladimirovich, biology teacher

Muromtsevskaya Secondary School (Muromtsevo, Sudogodsky District, Vladimir Region, Russian Federation)

Bykov Yury Aleksandrovich, researcher of Science and Ecological Education Department

Meshchera National Park (Gus-Khrustalny, Vladimir Region, Russian Federation)

Matyukhin Aleksandr Vladimirovich, candidate of biological sciences, researcher of Bird Ringing Center A.N. Severtsov Institute of Ecology and Evolution of the Russian Academy of Sciences (Moscow, Russian Federation)

Abstract. In this paper the authors consider sex ratio in populations of the bloodsucker of the genus Ornithomya Latreille located in the Vladimir and Murmansk Regions. During the ringing of birds since 2014 we have been collecting the bloodsucker flies parasitizing on them. For just four years in the Vladimir Region we have examined 12515 birds, from which 94 females and 17 males of the bloodsucker Ornithomya avicularia L., 1758, as well as 142 females and 37 males Ornithomya fringillina Curtis, 1836, were taken. On the territory of the Murmansk Region in 2016 and 2017465 females and 91 males of Ornithomya chloropus Bergot, 1901 were collected from birds. As a result of our research we obtained and summarized original material on the composition of the sexual structure of the population in bloodsucker flies (Diptera, Hippoboscidae) belonging to the genus Ornithomya Latreille, 1802. Females dominate males in Ornithomya avicularia, Ornithomya chloropus and Ornithomya fringillina in populations located on the territory of the Vladimir and Murmansk Regions of the Russian Federation. The study of seasonal changes in the sexual structure of the above species showed a gradual decrease in the number of male individuals during the season.

Keywords: gender structure of population; males; females; bloodsucker flies; bird parasites; hematophagous; Vladimir Region; Murmansk Region; Meshchera National Park; genus Ornithomya; Ornithomya avicularia; Ornithomya chloropus; Ornithomya fringillina; Diptera; Hippoboscidae; bird ringing; frequency of bloodsucker occurrence; seasonal dynamics of bloodsucker number.

УДК 574.2

DOI 10.24411/2309-4370-2019-11115

Статья поступила в редакцию 21.12.2018

\section{АКТИВНОСТЬ КАТАЛАЗЫ ТРАВЯНИСТЫХ РАСТЕНИЙ В УСЛОВИЯХ ЗАГРЯЗНЕНИЯ ГОРОДСКОЙ СРЕДЫ}

(C) 2019

Петухов Александр Сергеевич, магистрант кафедры органической и экологической химии

Хритохин Николай Александрович, кандидат химических наук,

профессор кафедры неорганической и физической химии

Кремлева Татьяна Анатольевна, доктор химических наук,

заведующий кафедрой органической и экологической химии

Петухова Галина Александровна, доктор биологических наук, профессор кафедры экологии и генетики

Тюменский государственный университет (г. Тюмень, Российская Федерация)

Аннотация. Поступающие в клетки растений поллютанты способны вызывать биохимические нарушения, в том числе перекисное окисление липидов, что приводит к изменению активности антиоксидантной системы. Поддержание окислительно-восстановительного равновесия в клетках является необходимым условием выживания растений в условиях антропогенного загрязнения. Целью работы было изучение активности каталазы в мятлике луговом, мышином горошке, клевере красном, мать-и-мачехе и ромашке вблизи различных промышленных предприятий г. Тюмени. Растения были собраны вблизи автотрассы, а также в районах аккумуляторного, моторостроительного, нефтеперерабатывающего и металлургического предприятий. Изменение активности каталазы в клетках растений оказалось видоспецифичным. В клетках мятлика лугового и мышиного горошка наблюдалось снижение активности каталазы, а в мать-и-мачехе, клевере красном и ромашке - как снижение, так и активация фермента. Поллютанты всех изученных предприятий оказывали в той или иной степени влияние на активность каталазы, однако наибольший эффект был зарегистрирован вблизи металлургического завода, что, вероятно, связано с высоким поступлением тяжелых металлов в растения. Наименьшее воздействие на активность каталазы по сравнению с контролем было обнаружено вблизи автотрассы.

Ключевые слова: каталаза; загрязнение окружающей среды; городская среда; растения; тяжелые металлы; мятлик луговой; мышиный горошек; клевер красный; мать-и-мачеха; ромашка; перекисное окисление липидов; антиоксиданты; ферменты; видоспецифичность; ответная реакция организма.

\section{Введение}

Произрастание растений в неблагоприятных условиях среды оказывает влияние прежде всего на их биохимический статус, что проявляется в изменении жизнедеятельности. Поступающие в клетки организма поллютанты могут накапливаться и вызывать различные биохимические нарушения [1]. Одним из наиболее важных процессов повреждения клеток на 